\title{
Operation Mode Analysis-Based National Sports Non-Profit Organization Modern Administrative Research
}

\author{
Qiang Qin*
}

Zhejiang University of Science and Technology, Hangzhou 310023, Zhejiang, China

\begin{abstract}
With market economy society development, non-profit organizations play irreplaceable roles in making up market failure and government failure aspects, and have become one of indispensable parts in "government-marketsociety" ternary structure society. Non-profit sports organizations development has become main direction of modern sports development, and become important carriers to develop national fitness activities, construct sports power. The paper through consulting relative literatures, makes summarized research on formers research results, and applies case analysis method, induction and deduction method these research methods, relates Chinese non-profit sports organizations operating mode, respectively analyzes Chinese non-profit sports organizations operating status from market establishing alliance mode and government setting up contract cooperation mode two aspects, analyzes some cases involved non-profit sports organizations operating status and the operating mode merits, finally it gets that how China to carry out modern sports non-profit organizations administration so that can provide references for national sports non-profit organizations administration and propel to its better development.
\end{abstract}

Keywords: National fitness, non-profit, operating mode, sports organizations.

\section{INTRODUCTION}

In the 80 s of 20 th century, non-profit organizations attracted international society attentions; its emergence played important roles in whole world, and changed the whole world. Just like professor Salamon proposed "One global social community revolution that started by non-profit organization is booming, its emergence will bring into great significance to $21^{\text {st }}$ century just as national states emergence important significance in $20^{\text {th }}$ century" [1]. As modern civil society one kind of basic social organization form, non-profit organization, and performed effects is of equal importance as market and government, all are for maintaining social stability and harmony. In the background of market failure, government failure and contract failure, non-profit organizations emerge at the right moment [2]; its emergence lets people to re-check government and market effects in driving social development, which has important effects on fostering democratic value, meeting social diversity demands, restricting government right, promoting public product supply and other aspects [3].

In sports field, nation issued "national fitness plan outline", which let masses sports activities to be extensively organized, promoted people positivity in participating in sports activities, which not only strengthened people's physique, but also greatly promoted Chinese sports development [4].

In contemporary, non-profit organizations development has already become main parts in modern sports development [5]. In "national fitness plan outline", it regulated "masses organizations and social communities play important roles in organizing masses sports activities, they act as the roles of establishing sound industry, system sports association and other masses sports organizations, it is beneficial to gradually form into national construction organizational network." In 2008 Beijing Olympic games and Paralympic Games summarizing commendation conferences, chairman $\mathrm{Hu}$ JinTao proposed "Propel to national basic level cultural sports organizing construction, encourage and support sports type of private non-enterprise unit and other masses sports organizations to positive develop national fitness exercises". And pointed out that after Olympic Games, China should implement transformation from main sports country to sports power. He called on deepening develop national fitness exercises, constantly striving to promote competitive sports levels, gradually implementing China move from main sports country towards sports power [6]. To implement the goal, if only rely on sports administrative department, it is hard to realize modern sports social development requirements, just at this time, non-profit organizations emerge at the right moment, and gradually grows and expand, become important paths of organizing national fitness activities and constructing sports power. Folk sports organizations, clubs, associations and other non-profit sports organizations not only can propel to people enhance health, strengthen physique, but also can make up society public goods and services supplying shortcomings, and change status that purely rely on government to provide sports public services.

\section{THEORETICAL BASIS AND CORRELATION MODEL ESTABLISHMENT}

In domestics and overseas existing literatures, they rarely mentioned about non-profit sports organizations, let alone its 
definitions. Though in relative literatures, there is no effective definition on non-profit sports organizations, we can find similar statement, such as, folk sports organizations, sports associations and also sports social community. Combine with lots of scholars opinions, the paper thinks non-profit sports organizations refers to established public welfare organizations that don't aims at gaining profits, while use sports voluntary behaviors to make contributions to society and meanwhile propel to public welfare establishments development, which contain all kinds of sports organizations, sports communities, sports clubs, sports kinds of private non-enterprise units, non-profit sports public institutions and sports foundation and so on.

For sports non-profit organizations effects on sports development, regarding non-profit sports organizations operating mechanism and enterprise running research, in the article " South Korea Olympic sports development foundation operating ways exploration and references", Qiu Ye made all-round introduction of South Korea Olympic sports development foundation history and legal status, mission and organizing institution, market operating operational mode, and put forward experience suggestions that China's sports foundation could reference from them, one of them was applying market operating mode, establishing feasible competitive lottery games so as to reserve funds for Chinese sports foundation; two was relying on society, government, individual and other communities as well as multiple channels to jointly raise strength, funds, arousing all aspects positivity and enriching sports funds;Third was scientific applying year 2008 Beijing Olympic Games' surplus funds so that reserving more funds for sports foundation and making greater contributions to Chinese national sports development.

In Tan Jian-Xiang issued article "Chinese public stadium enterprise-oriented reformation basic features and system conceiving", he thought that after China joining in world trade organization, due to confront career management system reformation, service industry re-tracking and other challenges, China urgently needed to carry on enterpriseoriented reformation on traditional stadium operational mode, and pointed out stadium reformation and development future trend enterprise-oriented operating and management, public welfare was still the main goal of public stadium serving to society, public stadium operation process presented particularity, public stadium sustainable development needed to constant intensify sports administrative department management, after that he proposed public stadium implementation of enterprise-oriented reformation's system conceiving :

$>$ According to features, make sort management on nonoperating assets and operating assets;

$>$ Implement separation among property right, management right and administration right;

$>$ Change public service and expense payment ways, let it to establish government and stadium market relations;

$>$ Constantly perfect public stadium enterprise-oriented management system.

Jiang Jian in "Shanxi province public sports clubs management system and its operating mechanism status analysis", by questionnaire survey, interview discussion method, he made investigation and research on Shanxi public sports fitness clubs management status, analyzed present existing difficulties and problems, and put forward suggestions to solve the problems.

Since 70s of 20th century, north America and Europe some places research on non-profit organizations are rapidly increasing, in the research, they also form into several kinds of theories of universal recognition, as market failure, government failure, administration theory and voluntary failure theory, they mainly apply economics method to state non-profit organizations existing problems, and from the research on market failure and government failure, they point out government and market existing drawbacks, these more verify non-profit organizations existing necessity. Among them, voluntary theory mainly illustrates non-profit organizations existing drawbacks in development that mainly present in charitable deficiency, such as charity narrowness, charity amateurism and charity paternity. Their main fund sources and expenditure have huge gap, non-profit organizations main features are public welfare and voluntary, main public products source are mainly relying on government funding, charging and social contribution. But due to non-profit organizations own lower public trust, public contribution consciousness not strong and other reasons, social contributions tend to be little, therefore government funding becomes main economic sources of non-profit organizations, but because new public management movement and government building movement, non-profit organizations received funding becomes little and little. And how to administrate non-profit organizations in the hope of making up these drawbacks, non-profit organizations should take initiative to change original management and operating modes, and try to new operating mode.

Public welfare property right executors define non-profit organizations asset aspect so as to distinguish state-owned property from privately-owned property. Public welfare property right is proposed on the basis of non-profit organizations property particularity, its fund sources are also plentiful, such as government funding, social contribution, membership dues and self management activities income, all of these distinguish from profit organizations, because their property is protected by relevant departments, non-profit organizations, due to suffer "Allocation principle ban" limitation, they themselves have no right to allocate property and surplus, state formulates non-profit organizations tax incentives so as to spread "pubic welfare property" concept, tells public and contributor their contributed property doesn't belong to specific person, but social public, and then encourage more contributors to participate in such activities. In addition, it cannot let non-profit organizations received legal status to superior to profit organizations due to "public welfare property", but non-profit organizations as civil subjects, they have same civil right ability as profit organizations, and also should carry on civil business activities, trade with other civil subjects, get involve in accepting donation, leasing houses and lands, paid service and selling products, and should sign contracts with trade objects, and have same legal status as other civil subjects. 
In the $80 \mathrm{~s}$ of last century, in America and Britain as well as other western countries, one kind of new public management theory sprung up. Different countries named new public management theory different, but most of them advocated to trigger market competition risk mechanism, took market or customer as guide, adopted private department management theory, technique and method, readjusted nation, society and market the three relations, so that could promote public service quality and public management level, let public service to be able to bring into more contributions and output to public.

New public management theory advocates that public service subject not only is government such national political institution, but also contains such dedicated in public interest service non-profit departments in the world, so public management subject according changes into such staff that pursues public interest services. Public management also calls administrative management; its management way is different from government. It not only needs government management such leading actor, but also needs other lots of supporting roles.

New public management theory advocates to take market as orientation, improve government and public relations, transfer from original "controlled administration" into "service administration", take public priority as principles, regard public as participation subject so as to ensure public service quality and efficiency; define government limited liability, and well solve government own positioning problems, better allocate government responsibilities, define what government should administrate and what not, government changes previous all controlled roles, transfers right and responsibility to non-profit organizations and private departments as well as the third department; Comprehensive introduce competition mechanism, strive to promote working efficiency, let more and more private departments and other non-profit organizations to participate in and provide public services so that can save government expenditures, and promote working efficiency as following Fig. (1).

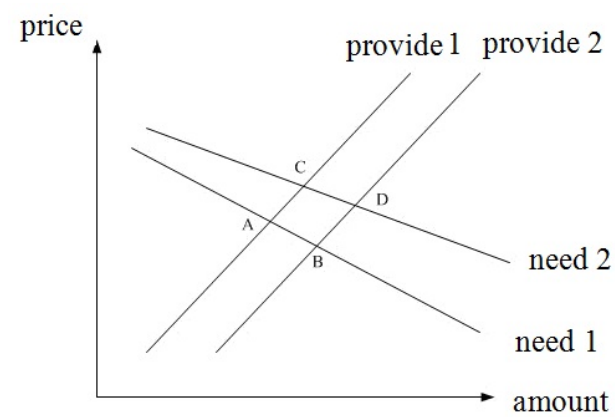

Fig. (1). Provide the relationship between quantity and price.

The paper through analyzing non-profit organizations development and its operating mode analyzes from establishing alliance mode with market and government setting up contract cooperation mode two aspects, and researches as well as analyzes its implementation existing problems, and puts forward reasonable and effective solution ways. The paper mainly adopts literature analysis method, induction, deduction method, empirical research and theoretical research combination and case research method.
Literature analysis method is relative favored research method when most of scholars make research, by distinguishing, collecting, sorting out literatures and other method, it does research and handling with its literatures so that form into scientific recognition method on fact, and then through CNKI net and Wanfang database searching, consults papers that are related to the text, according to research task demands, then consult and collect as well as apply lots of relevant literatures information, and then lets paper frame design to have plentiful designing materials. He paper mainly collects and sorting non-profit organizations operating mode relative researches, and on the basis of previous scholars' research results, combines with Chinese sports field nonprofit sports organizations development status, makes analysis and handling with its practical operation process status and appeared problems, finds out contemporary non-profit sports institutions organizations administrative new method.

After reading lots of relevant literatures, by abstract summarizing, it concludes relevant non-profit sports organizations operation mode concept, by concluding different data and observation materials obtained from different ways, and then analyzes non-profit sports organizations operating mode applying status in establishment, so as to let it to promote to certain theoretical height.

The paper mainly combines with China's football association and numerous enterprises cooperation, Guangdong province's Foshan city Chancheng district eleven stadiums and district government cooperation cases, applies voluntary failure theory, public welfare property theory, new public management theory, analyzes Chinese non-profit sports organizations operation mode, and forms into corresponding solving schemes, and finds out corresponding theoretical basis to support.

\section{RESEARCH RESULT AND ANALYSIS}

According to civil administration to non-profit organization classification standard, non-profit sports organizations in China will have sports communities, sports foundation, sports type of private non-enterprise units and other forms. No matter from the perspective of quantity or scale, sports community has already become contemporary China nonprofit sports organizations main part. According to civil administration folk management organizations statistical information indication, until 2008, communities in nationwide and trans-provincial includes autonomous regions and municipality activities are totally 229681 pieces, and sports communities are 11780 pieces that occupy $5.2 \%$ of nationwide and trans-provincial (autonomous regions and municipality) activities communities total amount; national communities are totally 1781 pieces, from which national sports communities that registered in civil administration department are totally 93 pieces that occupy $5.2 \%$ of national community registering total amount as Fig. (2).

By investigating national sports communities up most fund sources, government provided fiscal appropriation and allowance occupy maximum proportions that are up most economic sources of them. Make statistics of its sources distribution.

Correspond to above data, draw "black-white bar figure", as Fig. (3). 


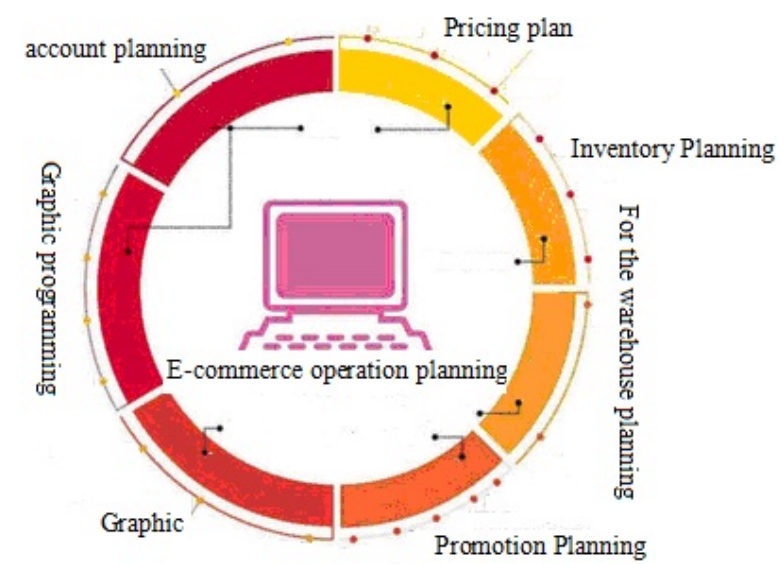

Fig. (2). Criteria for the classification of civil administration of non-profit organizations.

From above analysis, it is clear that there are 58 communities that occupy $70.7 \%$ of investigation total amount, rank second is various social donation, totally 38 communities funds come from here, they occupy $46.3 \%$ of investigation total amount, rank the third is membership fee, it totally has 32 communities that occupy $39.1 \%$ of investigation total amount, last item is paid service, it totally has 24 communities, the item occupies $29.3 \%$ of investigation total amount, at last rest 20 communities, their funds have other sources, they occupy $24.4 \%$ of they occupy $24.4 \%$ of investigation total amount.

Government provided fiscal appropriation and allowance have become undertaking sports organization upmost fund sources, the fund occupies proportion is larger. For undertaking sports community fund sources, it makes statistics.

Correspond to above data, draw "black-white bar figure", as Fig. (4).

Correspond to above data, draw "black-white bar figure", as Fig. (5).

For self-governing mass organizations, their structure distribution is as Fig. (6) self-governing mass organizations institution distribution.

For sports non-profit organization modern administrative research, we get its PDCA circulation recursion ascend graph, as Fig. (7).

According to statistics, by far China still has $96.3 \%$ sports communities suffered fund difficulties. For national sports communities, there are also province and city regional level non-profit sports organizations, undertaking sports communities, all trouble with same problem that is little fund raising path, income structure irrational phenomenon, their main economic sources are mainly government funding, but only rely on theses funding, it will prone to cause organization

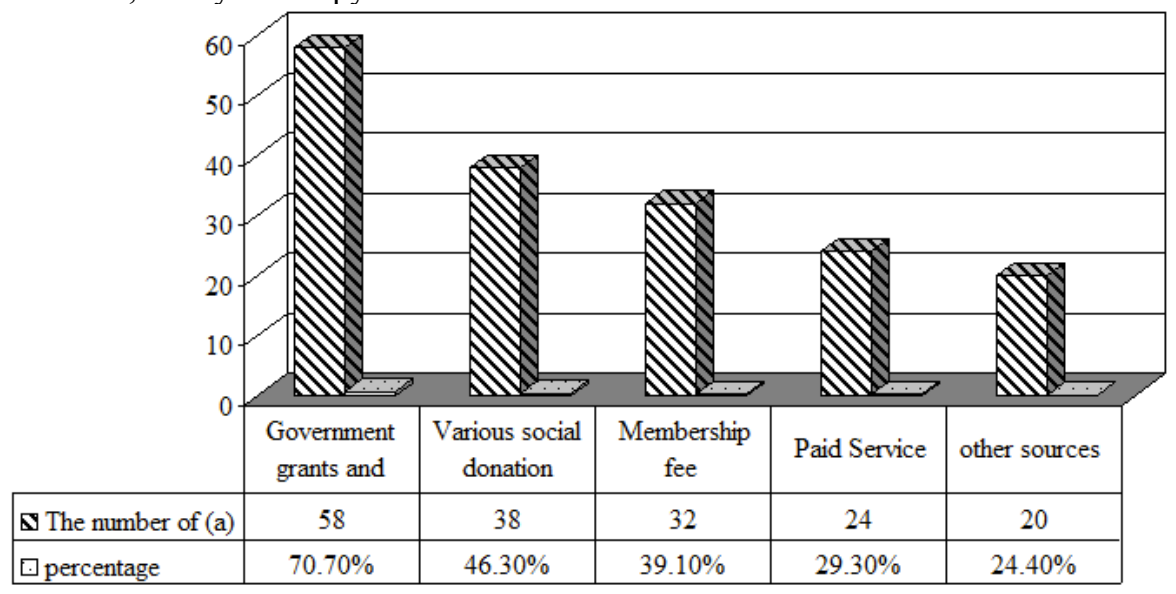

Fig. (3). China's community funding sources.

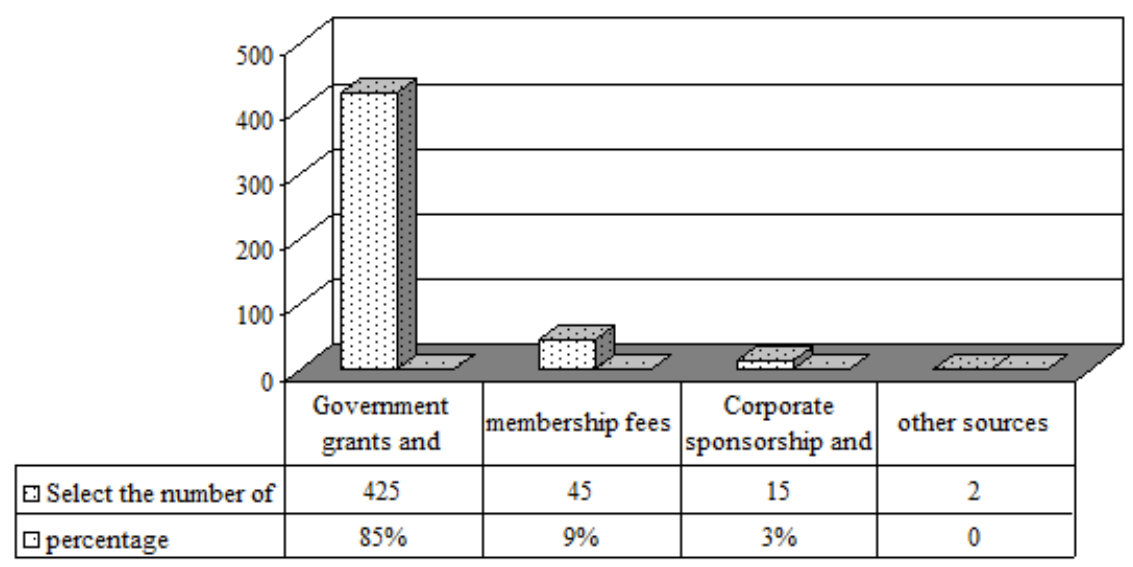

Fig. (4). Entrepreneurship sports community funding sources. 


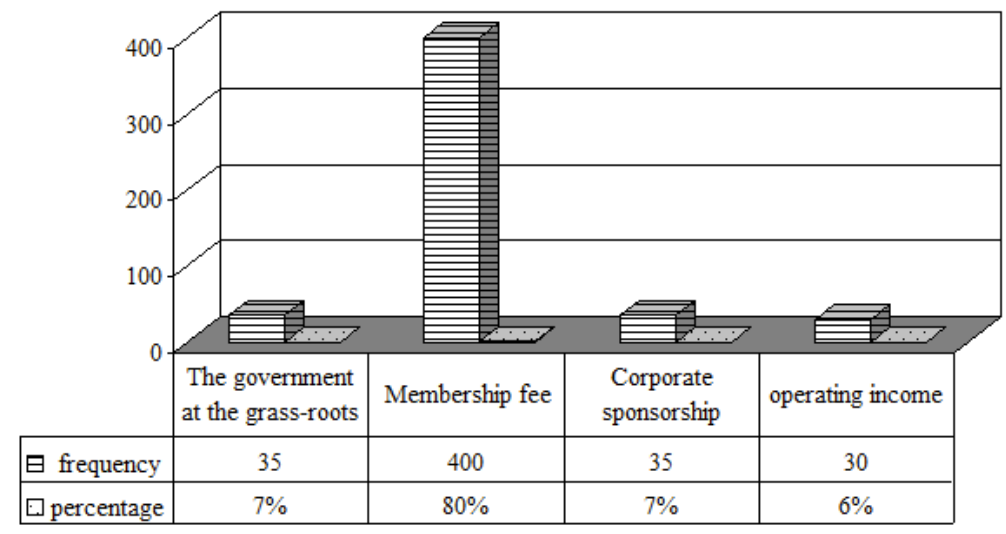

Fig. (5). Mass organizations of self-government funding sources.

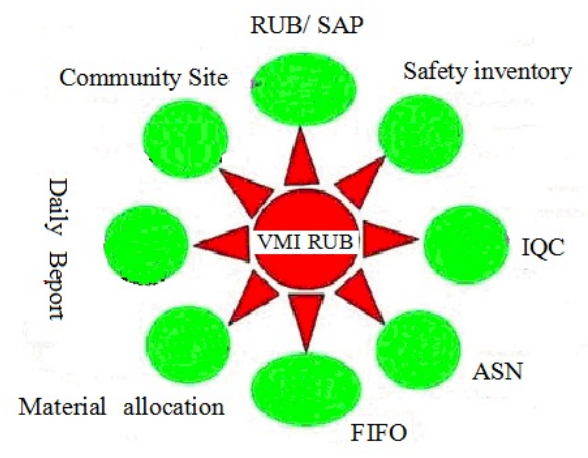

Fig. (6). Mass organization institution of the organization.

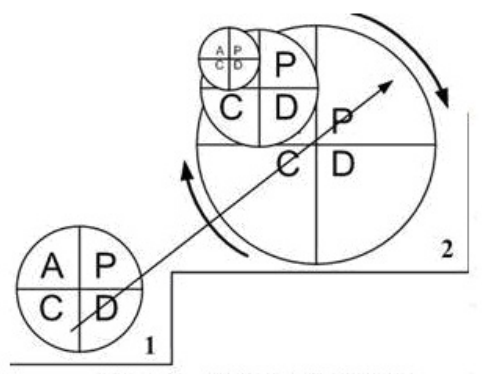

Fig. (7). PDCA cycle recursion rose diagram.

self creative ability deficiency, larger dependence on government and they themselves are hard to independent operate. All of these are existing problems in Chinese non-profit sports organizations. Due to obtained funding from other enterprises is little, and then dependence on government become larger, so in administrative process, nation should more focus on cooperative relations with enterprises to promote and strengthen their cooperative relations and implement win-win.

\section{CONCLUSION}

In recent ten years, Chinese non-profit sports organizations are springing up, they makes huge contributions to propel to social development and progress, and followed by western political reformation tide, non-profit organizations also confront numerous problems, fund shortage, fund insufficient, talents shortage, weak organizing ability, imperfect internal management, aftereffect inadequacy of development and so on, in order to solve these problems, promote Chinese sport better development, administration on China non-profit organizations are prominent very urgent. Non-profit sports organizations need having operating thoughts and modes so that can better maintain self-survival and development.

Chinese non-profit sports organizations operation mode not only can establish allies with market, but also can sign contract with government to cooperate. Their operating mode is as Fig. (8).

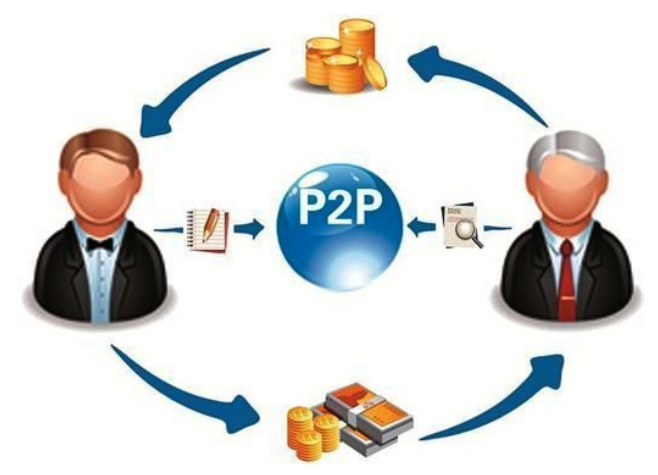

Fig. (8). The operation mode of the non-profit sports organizations.

Important reasons for Chinese non-profit sports organizations and market establish allies mode are considering from enterprise profit perspective, they have the aid of non-profit sports organizations public welfare characteristics to implement its enterprise interest increasing purposes; non-profit sports organizations consider cooperate with enterprises, and learn from enterprises matured operating management, financial management, performance evaluation and human resources management as well as other experiences, absorb enterprises advanced operating ways so as to obtain more investment to relieve fund shortage, it has various of forms that mainly has sponsor in fund, funding in enterprise industries products, help in technology, common cooperative product and also foundation development.

For non-profit sports organizations, firstly it should recognize in thought that set up contract mode with government is an important effect that non-profit sports organizations exert in modern sports functions and sports undertakings, which is also trial of new operating mode. In the other hand, it should remain organizations independence, promote public services levels and strengthen public trust, and further re- 
ceive government and social trust to arrive at two party's cooperation best effects, and promote cooperation win-win, national sports movement. And social public should support non-profit sports organizations and government setup contract mode, should participate in non-profit sports organizations provided sports public services with positive mood, timely get social feedback, accept social public monitoring, get people response, obtain timely adjustment and make timely solution.

\section{CONFLICT OF INTEREST}

The author confirms that this article content has no conflict of interest.

\section{ACKNOWLEDGEMENTS}

Declared none.

\section{REFERENCES}

[1] J. Cai, B. Fan, and J. Wang, "A survey of residents' satisfaction degree for urban public sport services," Journal of Beijing Sport University, no. 6, pp. 22-32, 2009

[2] Y. Chen, and G. Ma, "An empirical study on community sports service residents' satisfaction index model," China Sport Science and Technology, vol. 45, no. 4, pp. 11-19, 2009.

[3] Y. He, and M. Xu, "Study on evaluating system of sports consciousness of community residents in southwest cities," Journal of Chengdu Physical Education Institute, vol. 33, no. 2, pp. 43-45, 2007.

[4] B. Liu, S. Hu, H. Xu, and J. Gao, "Indices of the equality of essential public health services in China," Chinese Journal of Health Policy, vol. 2, no. 6, pp. 13-17, 2009.

[5] G. Wang, and W. Zhang, "Construction of the evaluation index system of city community sports-taking shanghai as an example," Journal of Chengdu Physical Education Institute, vol. 36, no. 2, pp. 34-50, 2010.

[6] D. Zhang, and M. Li, "Studies on evaluation index system of public sports facilities development level in China," China Sport Science, vol. 33 , no. 4 , pp. 3-23, 2013.

Received: June 10, 2015

Revised: July 29, 2015

Accepted: August 15,2015

(C) Qiang Qin; Licensee Bentham Open.

This is an open access article licensed under the terms of the (https://creativecommons.org/licenses/by/4.0/legalcode), which permits unrestricted, noncommercial use, distribution and reproduction in any medium, provided the work is properly cited. 